\title{
CARREIRA E SUCESSO EM UMA REVISTA DE NEGÓCIOS: uma análise à luz da quantofrenia gerencialista
}

\section{1- Carmem Ligia lochins Grisci*}

Doutora em Psicologia pela Pontifícia Universidade do Rio Grande do Sul, Brasil.

Professora do Programa de Pós-Graduação em Administração da Universidade Federal do Rio Grande do Sul (PPGA/EA/UFRGS), Brasil.

cligrisci@ea.ufrgs.br

http://lattes.cnpq.br/1123038118413853

\section{2- Wagner Soares Fernandes dos Santos}

Doutorando em Administração pela Universidade Federal do Rio Grande do Sul (PPGA/EA/UFRGS), Brasil. wagnersoaresfernandes@yahoo.com.br http://lattes.cnpq.br/3028592314719374

\section{3- Rodilon Teixeira}

Mestre em Administração pela Universidade Federal do Rio Grande do Sul (PPGA/EA/UFRGS), Brasil. teixeira@via-rs.net

http://lattes.cnpq.br/2090328410597420

\section{4- Wagner Rocha Gomes}

Mestre em Administração pela Universidade Federal do Rio Grande do Sul (PPGA/EA/UFRGS), Brasil. wagnergomes_73@yahoo.com.br http://lattes.cnpq.br/9484609934802714

\section{5- Felipe Santos Machado}

Mestre em Administração pela Universidade Federal do Rio Grande do Sul (PPGA/EA/UFRGS), Brasil. professorfelipemachado@gmail.com http://lattes.cnpq.br/0016208391442640

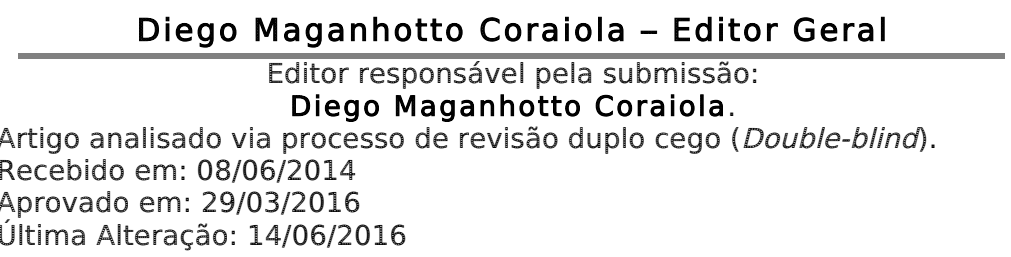

\footnotetext{
* Contato Principal: Rua Washington Luiz, 855, Sala 424, Centro Histórico, Porto Alegre/RS
} 


\title{
CARREIRA E SUCESSO EM UMA REVISTA DE NEGÓCIOS: ANÁLISE À LUZ DA
} QUANTOFRENIA GERENCIALISTA

\begin{abstract}
RESUMO:
À luz do conceito de quantofrenia gerencialista (Gaulejac, 2007) tomado em sua relação com o estilo de vida característico da sociedade líquido-moderna (Bauman, 2009), o presente estudo indagou: como uma revista popular de negócios vem apresentando as noções de carreira e sucesso ao longo dos últimos anos? E objetivou destacar e analisar as noções de carreira e de sucesso apresentadas por uma revista popular de negócios. Elegeu-se a revista Você S/A para o estudo por considerar-se que ela atua na divulgação e legitimação da lógica gerencialista que contempla a quantofrenia. A coleta de dados privilegiou as chamadas de capa de suas 156 edições publicadas em treze anos (1998-2011). A técnica de análise de conteúdo evidenciou o uso de números e o modo explícito ou latente de apresentação das categorias carreira e sucesso. Os números apontaram dicas, lições, atitudes, ideias e ações que, na arena das escolhas plurais, orientam o estilo de vida (Giddens, 2002). A intensificação do uso de números com destaque evidenciou a quantofrenia relacionada às categorias carreira e sucesso. Prescritiva dos modos de ser e agir para a obtenção de sucesso profissional, a quantofrenia se mostrou implicada ao estilo de vida demandado pelo trabalho.
\end{abstract}

Palavras-chave

Sociedade líquido-moderna; Quantofrenia; Carreira; Sucesso; Estilos de vida.

\section{CAREER AND SUCCESS IN A BUSINESS MAGAZINE: ANALYSIS THROUGH A QUANTOPHRENIAN MANAGEMENT PERSPECTIVE}

\begin{abstract}
This study used the concept of quantophrenia (Gaulejac, 2007) in the liquid-modern society (Bauman, 2009) to investigate how a popular business magazine has presented concepts regarding career and success over the last several years. The study sought to highlight and analyze the concepts of career and success presented by a popular business magazine. Therefore, the magazineVocê S/A was selected because it operates to divulge and provide legitimacy for the management rationale that includes quantophrenia. The data collection prioritized its cover stories in the 156 editions published over thirteen years (1998-2011). The content analysis technique revealed the use of numbers and the explicit or latent manner of presenting career and success categories. The numbers showed tips, lessons, attitudes, ideas, and actions that, in the arena of plural choices, provide orientation for lifestyles (Giddens, 2002). The intensification of the use of highlighted numbers showed the quantophrenia related to the categories for career and success. Quantophrenia is prescriptive regarding the ways of being and acting to obtain professional success, and was implied in the lifestyles demanded by work.
\end{abstract}

\section{Keywords}

Liquid-modern society; Quantophrenia; Career; Success; Lifestyle. 


\section{Introdução}

A sociedade líquido-moderna é aquela afeita a mudanças em tempo mais curto do que o necessário para que seus membros se habituem a elas. Associada à ideia do jogo curto, dos finais rápidos e indolores, da eliminação de ancoradouros, do desapego pela experiência e do descarte, aponta para indivíduos envoltos em incertezas e instabilidades, e aproxima-se dos modos de trabalhar promovidos pela lógica gerencialista (Bauman, 2009; Gaulejac, 2007; Sennett, 2009.).

A lógica gerencialista acentua a premência do curto prazo e promove o culto do desempenho e do resultado no aqui e agora. Sustenta-se atrelada ao desejo de progredir e à celebração do mérito chancelado pela medição de resultados. Supostamente distanciada de modelos autoritários, se vê familiarizada com práticas de sedução que, não raro, resultam adesão voluntária e acrítica. Envolta em regras racionais, prescrições precisas e instrumentos de medida sofisticados, apresenta-se com pretensa neutralidade e cientificidade, sob a proteção da racionalidade fria e objetiva dos números que se vê ilustrada na quantofrenia ou doença da medida (Gaulejac, 2007).

A quantofrenia, cabe adiantar, "designa uma patologia que consiste em querer traduzir sistematicamente os fenômenos sociais e humanos em linguagem matemática" (Gaulejac, 2007, p. 94). Ela se faz notar de modo usual em revistas populares de negócios que adotam linguagem inspirada em números, além de permitir alargar a compreensão relativa às noções de carreira e sucesso na sociedade líquido-moderna, que tomam assento particular na produção do estilo de vida a elas correspondente.

No tocante à carreira, ressaltam-se a carreira sem fronteiras (Defillippi \& Arthur, 1994), e a proteana (Hall \& Mirvis, 1996). A primeira atravessa as fronteiras entre organizações e se alicerça em redes de relacionamento ou informação para além da organização, prevendo que os indivíduos se distanciem da estabilidade da carreira tradicional a ser vivida em uma única empresa. A segunda associa-se ao mito das águas chamado Proteu, que, de súbito, metamorfoseava-se frente às necessidades impostas pelo cenário, revelando um esforço individual de adaptação correspondente à vida líquida a ser vivida na sociedade líquido-moderna, não raro estampado em revistas populares de negócios. Wood e Paula (2002) e Strinati (1999) afirmam, inclusive, que a cultura popular transmitida pelos meios de comunicação de massa assume importância sobre a vida dos indivíduos nas culturas ocidentais e são validadas por meio de empresários de destaque e gurus da área.

A noção de sucesso, por sua vez, perpassa as diversas camadas sociais na forma de senso comum divulgada pelas revistas de negócio que, em geral, está "relacionada, predominantemente, aos aspectos materiais, como renda e riqueza, além de elementos como reconhecimento, prestígio, status" (Ituassu \& Tonelli, 2011, p.13). Uma carreira bem-sucedida contemplaria características da carreira proteana e indicaria uma posição privilegiada do indivíduo em termos de estilo de vida que, na sociedade líquido-moderna, se regeria pela seguinte chamada: “Você tem apenas duas páginas e 40 segundos para se vender. Mas nós temos 25 regras para o seu currículo brilhar" $\left(2000, n^{\circ} 29\right)$. Alcançadas, as regras difundidas homogeneízam o estilo de vida vinculado ao sucesso; não alcançadas, excluem aqueles que delas se afastam, considerando-os como desviantes (Eccel, Grisci, \& Tonon, 2010).

A quantofrenia gerencialista tomada em sua relação com o estilo de vida característico da sociedade líquido-moderna constituiu o suporte de análise do objeto do presente estudo que indagou: como uma revista popular de negócios vem apresentando as noções de carreira e de sucesso ao longo dos últimos anos? A fim de respondê-la, objetivou-se destacar e analisar as noções de carreira e de sucesso apresentadas por uma revista popular de negócios. Para tanto, elegeu-se a revista Você S/A - publicação da Editora Abril - classificada na categoria negócios e carreira. Sua escolha deveu-se ao entendimento de que essa mídia atua na divulgação e legitimação da lógica gerencialista, sendo mais um elemento disseminador desse pensamento, além de abranger o país inteiro e ter disponibilidade de acesso fácil pelo público em geral.

Nas próximas seções serão apresentados os aspectos teóricos relativos ao objeto de estudo, o procedimento metodológico adotado, a apresentação e análise dos resultados e, por último, as considerações finais.

\section{Carreira e Sucesso à Luz da Quantofrenia Gerencialista na Sociedade Líquido- Moderna}

As possibilidades de satisfação das necessidades e dos desejos que desfrutamos atualmente não foram imaginadas ou experimentadas por nenhuma outra sociedade do passado (Bauman, 2009). Para sustentar o nível de atividade econômica dessa sociedade de consumo, têm-se utilizado, 
recorrentemente, artifícios sutis que transcendem o âmbito econômico e avançam para diversas dimensões da vida dos cidadãos-consumidores.

A sociedade de consumo não se baseia na satisfação das necessidades e desejos de seus membros, mas na promessa de satisfação dos mesmos. É nesse sentido que prescrições sempre renovadas no formato de receitas infalíveis atuam de maneira paulatina, fornecendo dicas por meio das quais os indivíduos poderiam vir a atingir o sucesso. Desse modo, a vida líquida é uma forma de vida que tende a ser levada adiante na sociedade líquido-moderna.

'Líquido-moderna' é uma sociedade em que as condições sob as quais agem seus membros mudam num tempo mais curto do que aquele necessário para a consolidação, em hábitos e rotinas, das formas de agir [...]. A vida líquida, assim como a sociedade líquido-moderna não pode manter a forma ou permanecer por muito tempo [ ...]. Em suma: a vida líquida é uma vida precária, vivida em condições de incerteza constante (Bauman, 2009, p. 7-8).

Na vida líquida observa-se um estilo de vida sempre implicado a nos constituir como um modo de existência. Ao contrário do que se poderia supor, a noção de estilo de vida não se restringe à área de consumo. Ele decorre do conjunto de escolhas cotidianas, e apresenta-se por meio de práticas rotinizadas, reconhecidas como rotinas incorporadas em hábitos de vestir, comer, modos de agir, lugares a frequentar (Giddens, 2002), revelando também os modos de ser.

Considera-se que o gerencialismo incorpora esses modos em suas características, uma vez que as ordens e proibições passam a ser compreendidas e interiorizadas como procedimentos e princípios consoantes à lógica organizacional. Manter-se produtivo transcende 0 ambiente de trabalho e alcança a vida do indivíduo submetido à gestão que rege seu tempo de trabalho e de nãotrabalho. Nesse sentido, pró-atividade, flexibilidade, mobilização psíquica e motivação passam a ser vistos como requisitos mínimos a serviço dos objetivos das empresas (Gaulejac, 2007). Importante considerar, ainda, a escolha de trabalho e do ambiente de trabalho como elementos básicos das orientações de estilos de vida na pluralidade de escolhas que se apresentam. Dizer isso, entretanto, não quer dizer escolhas abertas para todos, ou conhecimento pleno das alternativas possíveis (Giddens, 2002).

Condizente com esse contexto, revistas populares de negócios, como a Você S/A, tendem a adotar um tom normativo-prescritivo e voltam-se para o profissional com foco em estratégias e oportunidades de carreira. E “o leitor da Você S/A é um 'usuário' da revista, que representa para ele um instrumento de autoajuda e uma referência para os padrões de comportamento" (Wood \& Paula, 2002, p. 31). Em períodos de estagnação ou crise econômica, nos quais os profissionais tornam-se mais vulneráveis ao desemprego, o apelo a publicações com esse foco pode tornar-se mais recorrente. Como exemplo, a crise financeira de 2008 expôs as complexas inter-relações e vulnerabilidades do sistema financeiro mundial (Silva, 2010). Apesar desse episódio não ter afetado mais diretamente o Brasil (Velloso \& Albuquerque, 2009), moldou um ambiente turbulento e propício à intensificação de publicações relacionadas à carreira e ao sucesso.

Ao enfatizar o poder que esse tipo de publicação tem ao se tornar parte da vida das pessoas e influenciar as suas rotinas, Sant'Anna (2001) alerta que há muito a publicidade seduz, anunciando ser possível saborear o sentido da vida individualmente, no ato da compra e na fidelidade às marcas. A tarefa de ultrapassar-se no lazer e no trabalho transforma-se em regra, e os manuais de instrução sobre como ultrapassar os próprios limites para logo redimensioná-los, vendem-se como best-sellers, por oferecerem menos chances de fracasso.

Um novo segmento de mercado se sobressai na economia capitalista e cumpre a função de estimular o consumo de modos de viver ou estilo de vida agregados a mercadorias. Trata-se do controle-estimulação que se visibiliza, por exemplo, nos imperativos: 'Consuma!', 'Acesse!' (Mansano, 2009). A revista Você S/A prescreve normas de convívio que induzem o indivíduo a determinados comportamentos, podendo reduzir a percepção de suas opções de escolha frente ao caminho já traçado, posto e enumerado. Exemplos que ilustram essa situação são os enunciados acompanhados de promessa explícita de que em fazendo algo, sua vida vai melhorar. Isto identifica a indução clara a determinadas atitudes que as chamadas capa veiculadas, não só na revista Você S/A, traçam no cotidiano das pessoas. Uma vez inserido neste circuito - de produção e de consumo - o sujeito tende a ocupar sua existência com atividades que reproduzam a lógica do capital: o acúmulo de bens e o acesso a certas comodidades (Mansano, 2009).

“Os experts da gestão tornam-se pessoas que prescrevem modelos. Propõem encarregar-se dos negócios do mundo", diz Gaulejac (2007, p.63). Esses modelos são condizentes com a lógica do consumo da subjetividade, via ideologia gerencialista e seus pressupostos, crenças, hipóteses e métodos a necessitarem validação. "O paradigma objetivista dá um verniz de cientificidade à 
“ciência gerencial'” (Gaulejac, 2007, p. 66). É nesse sentido que se apresenta a quantofrenia compreendida como a doença da medida. Embora não seja algo novo, ela se mostra "recorrente nos meios que aplicam a qualquer coisa uma linguagem inspirada nas matemáticas. (...) O cálculo dá uma ilusão de domínio sobre o mundo. Os 'calculócratas' preferem a ilusão de garantia, em vez de uma realidade cheia de incertezas, que dá medo" (Gaulejac, 2007, p. 97). Em decorrência, afetos e emoções, por exemplo, perderiam a pertinência por não serem traduzidos em números, enquanto prevaleceria a crença oriunda de uma representação objetiva dos fenômenos decorrente dos números, uma vez que:

Esse instrumento de medida é uma expressão caricatural da ilusão que consiste em crer que a realidade possa ser compreendida e dominada com a condição de medi-la. Para fazer isso, recortamos essa realidade em partículas que pretenderíamos serem elementares, às quais atribuímos um coeficiente. Feitos o recorte e a cifração, todos os cálculos se tornam possíveis. Podemos resolver equações, estabelecer estatísticas, efetuar comparações. Acreditamos que desta forma estamos construindo uma representação objetiva dos fenômenos [ ...] (GAULEJAC, 2007 p. 95-96).

Para obter sucesso na carreira, o indivíduo é induzido a crer na importância de assumir a responsabilidade por construir conhecimentos, habilidades e atitudes condizentes com o que o mercado precisa, por vezes colocando-se em uma perspectiva de sucesso e (in)felicidade, conforme apontaram Tanure, Carvalho e Andrade (2007), em estudo relativo a executivos. Trata-se de desenvolver e cultivar uma marca Você S/A, o que poderíamos chamar de capital imaterial (Gorz, 2005). Em outras palavras, seria como um modo de produzir desejos e vontades de imagens de si mesmo e do estilo de vida que, adotado e interiorizado pelos indivíduos, transforma-os em uma espécie de consumidores que não necessitam daquilo que desejam e não desejam aquilo de que necessitam.

Entre esses artifícios está o estabelecimento e a consolidação de uma eterna insatisfação. E, para sustentá-la, o mercado tem oferecido produtos cada vez mais descartáveis ou com durabilidade reduzida. Com isso, uma estratégia utilizada para gerar a insatisfação tem sido a de propagar a depreciação e a desvalorização do produto pouco tempo depois de seu lançamento ou quando já há meios de substituí-lo. Outra estratégia, ainda mais eficaz, é promover a satisfação momentânea de necessidades, desejos e vontades de uma forma que seja provocado um recorrente despertar dessas mesmas necessidades, desejos e vontades. E o que começa de uma forma simples ou natural deve se tornar uma compulsão ou vício (Bauman, 2009).

Na perspectiva dessa concepção gerencialista, no contexto de uma sociedade líquido-moderna, o conceito de carreira sofre mudanças. Com o processo de enxugamento e redução dos níveis hierárquicos, as organizações passaram a valorizar o profissional flexível, facilmente adaptável a diferentes circunstâncias. Em detrimento das críticas recebidas desde seu surgimento, o termo carreira sem fronteiras (Arthur \& Rousseau, 1996) merece destaque. Dentre as características da carreira assim denominada, encontram-se a falta de linearidade na evolução profissional dos indivíduos, o aumento na incerteza das previsões sobre as trajetórias profissionais, o baixo índice de permanência em um mesmo emprego, a diminuição do vínculo empregatício e a transferência da responsabilidade do desenvolvimento profissional para o funcionário. A carreira sem fronteiras prevê o desenvolvimento de uma relação independente entre organização, indivíduo e mobilidade profissional, bem ao gosto da vida líquida.

Além da carreira sem fronteiras são encontrados outros modelos, como exemplificam a carreira proteana (Hall \& Moss, 1998) e a carreira de autogestão (Fontenelle, 2005). Ambas são propostas condizentes com uma nova concepção de trajetória de carreira, que têm em comum a desagregação do conceito de carreira da conexão com uma organização. Os estudos de Hall e Mirvis (1996) apontam que a concepção de carreira proteana tem como pressuposto básico a carreira ser conduzida pelo próprio indivíduo e não pela organização. Além disso, observam que a carreira deixa de significar um contrato do indivíduo com a organização para ser um contrato consigo mesmo. O que muda é o responsável principal pelo seu planejamento e administração: antes a organização, agora o trabalhador (Hall \& Mirvis, 1996). A carreira proteana também pode ser entendida como uma metáfora da carreira de autogestão (Fontenelle, 2005). Esse tipo de carreira tem uma concepção de indivíduo flexível, supostamente capaz de gerenciar o presente e o futuro de seu trabalho, assumindo o sucesso e o fracasso do seu trabalho.

Destarte, administrar a carreira aponta para o desenvolvimento da capacidade de responder, por si mesmo, às demandas da realidade assumindo diferentes formas ou papéis, continuamente pressionado pela necessidade de capacitação para obter vantagem em um ambiente de constantes mudanças (Fontenelle, 2005). Esta concepção de carreira é caracterizada pela 'fluidez', exigindo do trabalhador versatilidade e capacidade de se 'autoempresariar', assumindo os riscos pelas 
mudanças em sua trajetória profissional (Paiva, 1998). Esse 'eu empreendedor' é um atributo fundamental do indivíduo empregável, que precisa autogerir a carreira e enxergar-se como se fosse um negócio (Bridges, 1995).

\section{Procedimento Metodológico}

A fim de destacar e analisar as noções de carreira e de sucesso apresentadas por uma revista popular de negócios, tomou-se uma revista de grande circulação em território brasileiro que apresenta dentre seus tópicos editoriais os temas carreira e sucesso. A seguir apresentam-se a caracterização da revista escolhida para o estudo, bem como o procedimento utilizado.

\subsection{Caracterização da Revista Você S/A}

A revista Você S/A passou a ser publicada a partir de abril de 1998, em seu primeiro número, como um encarte da revista Exame. Segundo Wood e Paula (2002), os editores partiram da observação de que quando a Exame tratava de administração de carreira, trajetória profissional e qualificação profissional, a venda em bancas aumentava. Isso foi compreendido como sinal do interesse do público pelos temas. Ao contrário do assinante, o comprador de banca tenderia a adquirir a revista devido aos assuntos abordados em edições específicas. Desde o seu lançamento, a revista foi considerada sucesso de vendas.

Trata-se de uma revista que aborda em suas matérias temas relacionados à Carreira, Mercado e Dinheiro e se apresenta como "uma comunidade que busca a felicidade no trabalho e na vida pessoal", conforme divulga o site da Editora Abril (2014), responsável pela publicação da revista. A publicação, em geral, apresenta as seguintes seções: Agora, Dinheiro, Gestão da Carreira e Mercado. O público leitor da revista é composto de modo igual por homens e mulheres ( $50 \%$ cada); a faixa etária predominante encontra-se entre 25 e 34 anos, com 31\% dos leitores; seguida da faixa etária entre 35 a 44 anos, com $27 \%$. A classe social " $C$ " predomina, com $61 \%$ dos leitores. Na região sudeste concentra-se a maior parte dos leitores, representando $57 \%$ do público da revista (Estudos Marplan Consolidado, 2013 como citado em Editora Abril, 2014). Atualmente são distribuídos, mensalmente, cerca de 160 mil exemplares na revista impressa e no tablet, sendo que desse quantitativo 98 mil são assinantes. A revista também recebe mais de 800 mil acessos em seu site e possui mais de 800 mil conexões nas redes sociais (Editora Abril, 2014).

\subsection{Procedimento Utilizado}

O presente estudo analisou as noções de 'carreira' e 'sucesso' conforme apresentadas nas capas da revista Você S/A, em 156 edições publicadas no decorrer de treze anos (1998-2011). Tais edições foram organizadas em treze períodos, sendo cada período correspondente a um ano composto de doze edições em ordem sequencial de publicação. O primeiro período iniciou na edição no 2, em agosto de 1998 e finalizou na edição $n$ ㅇ 13, em julho de 1999 e assim, sucessivamente, até - 13 ำ período que se encerrou na edição no 157, em julho de 2011 . O primeiro número não foi incluído nas análises por ainda se tratar de um encarte da revista Exame. Uma vez organizado o material empírico, foram analisados os títulos das chamadas de capa de cada uma das revistas que somam os treze períodos equivalentes a treze anos de publicação. A análise foi realizada a partir da técnica de análise de conteúdo, conforme enfatizada por Minayo (2003, p. 74): “[ ...] o que está escrito, falado, mapeado, figurativamente desenhado e/ou simbolicamente explicitado sempre será o ponto de partida para a identificação do conteúdo manifesto (seja ele explícito e/ou latente)".

Procedeu-se, então, a leitura de todas as chamadas de capa de cada uma das edições da revista, na sequência de sua publicação, tendo como critério de seleção a presença explícita ou latente das noções de 'carreira' e 'sucesso'. Considerou-se presença explícita as chamadas que continham escritas as palavras 'carreira' ou 'sucesso'. Por exemplo, 'Como mudar de carreira aos

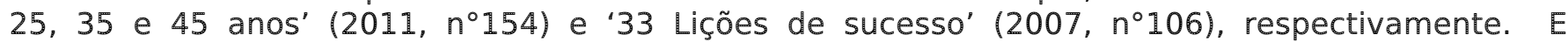
presença latente aquelas que possibilitavam inferir relação com as noções de 'carreira' e 'sucesso'. Por exemplo, '8 sinais de que você merece reconhecimento' (2010, $\left.\mathrm{n}^{\circ} 144\right)$. Posteriormente verificouse se o conteúdo da chamada de capa estava, de fato, desenvolvido dentro do corpo da revista. Em caso afirmativo, procedeu-se à comprovação de que a chamada de capa remetia a uma ou outra noção em análise.

Dessa pré-análise resultou a tabulação de dados com 213 chamadas de capa relacionadas, de modo explícito ou latente, às noções de 'carreira' e 'sucesso'. Das 156 edições, 132 apresentaram 
213 chamadas de capa relativas a tais noções. Para facilitar a visualização dos dados obtidos, as chamadas selecionadas foram relacionadas nas seguintes categorias: (1) Carreira; (2) Sucesso; e (3) Carreira e Sucesso. Sendo esta última formada por chamadas que contemplavam as categorias 'carreira' e 'sucesso', simultaneamente. Assim, chamadas como "Crash! Tomou um tombo na carreira? Levante-se e vá em frente" (1999, $\left.\mathrm{n}^{\circ} 17\right)$, depois de verificado e comprovado o desenvolvimento do conteúdo relativo à carreira dentro do corpo da revista, foram classificadas como carreira, uma vez que havia relação explícita com esta. Por fim, foram descartadas as chamadas apresentadas nas capas, depois de verificado e comprovado, dentro do corpo da revista, que seu conteúdo não estava relacionado com os temas objetos deste estudo. Assim, tais informações não se incluíram entre os dados a serem analisados.

Do total de 213 chamadas relacionadas com as categorias de análise propostas, 77 despertaram a atenção por contemplarem números, o que foi levado em consideração na análise. Um exemplo disso foi a chamada "56 Atitudes infalíveis para fortalecer sua carreira" (2009, n¹28). A seguir são apresentados os resultados e sua análise.

\section{Apresentação e Análise dos Resultados}

A Tabela 1 contempla o resultado da análise das capas de 156 edições da revista Você S/A relativas aos 13 anos de publicação. Buscou-se verificar percentualmente como estavam distribuídas as chamadas relacionadas aos temas 'carreira' e 'sucesso' nessas edições.

Tabela 1:

Total de edições sem e com chamadas de capa relativas às categorias carreira e sucesso - por período. Revista Você S/A - 132 edições

\begin{tabular}{|c|c|c|c|c|c|c|}
\hline Período & Sem & Carreira & Sucesso & $\begin{array}{l}\text { Carreira e Sucesso } \\
\text { (simultaneamente) }\end{array}$ & Soma & $\%$ \\
\hline 1 (ago/1998 a jul/1999) & 1 & 9 & 4 & 2 & 15 & $7,04 \%$ \\
\hline 2 (ago/1999 a jul/2000) & 0 & 15 & 0 & 3 & 18 & $8,45 \%$ \\
\hline $3($ ago/2000 a jul/2001) & 1 & 11 & 3 & 2 & 16 & $7,51 \%$ \\
\hline 4 (ago/2001 a jul/2002) & 1 & 14 & 0 & 0 & 14 & $6,57 \%$ \\
\hline 5 (ago/2002 a jul/2003) & 6 & 8 & 1 & 0 & 9 & $4,23 \%$ \\
\hline $6($ ago/2003 a jul/2004) & 2 & 10 & 1 & 1 & 12 & $5,63 \%$ \\
\hline 7 (ago/2004 a jul/2005) & 4 & 8 & 1 & 2 & 11 & $5,16 \%$ \\
\hline 8 (ago/2005 a jul/2006) & 4 & 5 & 3 & 1 & 9 & $4,23 \%$ \\
\hline 9 (ago/2006 a jul/2007) & 2 & 6 & 7 & 2 & 15 & $7,04 \%$ \\
\hline $10(\mathrm{ago} / 2007 \mathrm{a} \mathrm{jul} / 2008)$ & 1 & 25 & 4 & 1 & 30 & $14,08 \%$ \\
\hline 11 (ago/2008 a jul/2009) & 0 & 27 & 3 & 1 & 31 & $14,55 \%$ \\
\hline 12 (ago/2009 a jul/2010) & 1 & 14 & 0 & 1 & 15 & $7,04 \%$ \\
\hline $13(\mathrm{ago} / 2010 \mathrm{a} \mathrm{jul} / 2011)$ & 1 & 12 & 3 & 3 & 18 & $8,45 \%$ \\
\hline Total & 24 & 164 & 30 & 19 & 213 & $100,00 \%$ \\
\hline
\end{tabular}

Nota. Fonte: dados da pesquisa.

Da análise da Tabela 1, verifica-se o número reduzido de edições que não contemplaram chamadas de capa relacionadas com carreira e sucesso, com destaque para os períodos 5, 7 e 8 . De modo geral, do total de 156 edições analisadas apenas 24 não apresentavam chamadas com as categorias de análise, representando 15,3\% desse total. Assim, podemos constatar que a utilização recorrente dos temas 'carreira' e 'sucesso' nas chamadas de capa trata-se de uma prática usual da revista analisada.

Notou-se um aumento expressivo no número de chamadas relacionadas à carreira nos períodos 10 e 11. Tal resultado pode corroborar a ideia de uma forte intenção em promover o empreendedorismo e o foco na manutenção do emprego e do sucesso na carreira mesmo com os problemas econômicos enfrentados na crise econômica mundial de 2008, que teve origem no mercado imobiliário norte-americano. Nesse período, a desconfiança dos investidores nos sistemas financeiros se propagou em âmbito mundial por meio de fugas de capital e movimentos de pânico nos mercados de ações no período da crise. E isso poderia afetar fortemente, dependendo do ambiente institucional específico do sistema funcional, o lado real da economia, podendo resultar em períodos de recessão e depressão da atividade econômica, bem como em aumento das taxas de desemprego (Silva, 2010).

Embora a crise mundial não tenha afetado diretamente o Brasil por conta de sua menor vulnerabilidade externa no período, algumas políticas econômicas restritivas propostas pelo Fundo Monetário Internacional - que tiveram o intuito de reconquistar a confiança dos mercados refletiram-se nos países emergentes (Velloso \& Albuquerque, 2009). Desta forma, as revistas 
populares de negócios não poderiam se furtar da divulgação de receios acerca do mercado financeiro que poderiam afetar o mercado de trabalho. Ademais, os medos derivados da situação exposta provavelmente aumentaram a procura dos profissionais por melhorias na situação de suas carreiras, visando a preservação do emprego ou o incentivo ao empreendedorismo. Isso corrobora com a ideia apresentada pelas revistas de que você é o responsável pela sua carreira, manutenção ou mesmo mudança de emprego e melhoria contínua, como citado na chamada "Empregabilidade: crie o plano B e mantenha o rumo da sua carreira" (2008, n²120).

Neste mesmo período, nota-se uma associação entre os temas carreira e sucesso, o que pode representar uma tentativa de aproximação entre os dois conceitos como sendo complementares. De modo geral, nota-se que nos últimos anos a revista buscou enfatizar as chamadas relacionadas aos temas 'carreira' e 'sucesso' a partir da utilização desses conceitos de modo associado.

$\mathrm{Na}$ Tabela 2, a seguir, pode ser visualizado o uso de números nas chamadas de capa.

Tabela 2:

Uso de números nas chamadas de capa relacionadas às categorias de análise - por período. Revista Você S/A - 156 edições

\begin{tabular}{|c|c|c|c|c|}
\hline Período & $\begin{array}{c}\text { Total de } \\
\text { chamadas } \\
\text { (Carreira, } \\
\text { Sucesso, Carreira } \\
\text { e Sucesso - } \\
\text { simultaneamente) } \\
\text { (a) }\end{array}$ & $\begin{array}{c}\text { Uso de } \\
\text { números } \\
\text { nas } \\
\text { chamadas } \\
\text { (b) }\end{array}$ & $\begin{array}{l}\text { Percentual do uso } \\
\text { de números no } \\
\text { período sobre o } \\
\text { seu total dos } 13 \\
\text { períodos } \\
\text { (b) } \div \text { (c) }\end{array}$ & $\begin{array}{c}\text { Percentual do uso } \\
\text { de números sobre } \\
\text { o total de } \\
\text { chamadas do } \\
\text { período } \\
\text { (b) } \div \text { (a) }\end{array}$ \\
\hline 1 (ago/1998 a jul/1999) & 15 & 4 & $5,20 \%$ & $26,70 \%$ \\
\hline 2 (ago/1999 a jul/2000) & 18 & 2 & $2,60 \%$ & $11,10 \%$ \\
\hline $3($ ago/2000 a jul/2001) & 16 & 4 & $5,20 \%$ & $25,00 \%$ \\
\hline 4 (ago/2001 a jul/2002) & 14 & 2 & $2,60 \%$ & $14,30 \%$ \\
\hline 5 (ago/2002 a jul/2003) & 9 & 2 & $2,60 \%$ & $22,20 \%$ \\
\hline $6($ ago/2003 a jul/2004) & 12 & 7 & $9,10 \%$ & $58,30 \%$ \\
\hline 7 (ago/2004 a jul/2005) & 11 & 4 & $5,20 \%$ & $36,40 \%$ \\
\hline $8($ ago/2005 a jul/2006) & 9 & 6 & $7,80 \%$ & $66,70 \%$ \\
\hline 9 (ago/2006 a jul/2007) & 15 & 9 & $11,70 \%$ & $60,00 \%$ \\
\hline $10(\mathrm{ago} / 2007 \mathrm{a} \mathrm{jul} / 2008)$ & 30 & 7 & $9,10 \%$ & $23,30 \%$ \\
\hline 11 (ago/2008 a jul/2009) & 31 & 10 & $13,00 \%$ & $32,30 \%$ \\
\hline 12 (ago/2009 a jul/2010) & 15 & 8 & $10,40 \%$ & $53,30 \%$ \\
\hline 13 (ago/2010 a jul/2011) & 18 & 12 & $15,60 \%$ & $66,70 \%$ \\
\hline Soma & 213 & 77 (c) & $100 \%$ & - \\
\hline
\end{tabular}

Nota. Fonte: dados da pesquisa.

A Tabela 2 apresenta os totais por período, sendo possível observar a gradativa intensificação do uso de números. Ao verificarmos a evolução temporal no uso de número nas chamadas de capa da revista, podemos observar que, da criação da revista até o período no 8 , o quantitativo de chamadas de capa utilizando números era de 2 a 7. A partir do período no 9, as chamadas de capa passaram a utilizar números com maior frequência. No entanto, a partir de 2007 verifica-se um crescimento substancial em seu uso. Em especial, nos três últimos períodos que apresentam 10, 8 e 12 chamadas condizentes com quantofrenia. Com isso, quase que a totalidade das edições passou a utilizar essa forma de comunicação. No período no 13, por exemplo, doze das dezoito chamadas relacionadas às categorias de análise continham números. A Figura 1 apresenta alguns exemplos de chamadas de capa que podem ser relacionadas com características de quantofrenia.

São ilustrativas das 77 chamadas que apresentaram números: "61 Atitudes para turbinar sua carreira" (2002, n48) e "33 Lições de sucesso" (2007, n¹06). Considera-se que os números 61 e 33, em comparação aos números 60 e 30, poderiam suscitar a percepção de precisão relativa à informação, sobre a qual não teria ocorrido qualquer tipo de 'arredondamento'. A alusão matemática sugere confiabilidade e certa cientificidade às prescrições não-normatizadoras que as chamadas apresentam, apontando para a quantofrenia em seu objetivo de traduzir os fenômenos sociais e humanos em linguagem matemática.

Em uma observação analítica do uso de números, constatou-se a ocorrência de uma mudança significativa no transcorrer dos treze períodos. Comparativamente, nos períodos iniciais, os números eram pouco utilizados e escritos com numerais cardinais por extenso, enquanto nos períodos finais era mais frequente o uso de algarismos arábicos, com fontes de tamanho maior e cores mais intensas, o que os ressaltava na diagramação das capas. Assim, verificou-se que o 
próprio projeto gráfico da capa passou a dar maior destaque aos números. Na chamada “56 atitudes infalíveis para fortalecer sua carreira" (2009, n¹28), o número ocupa aproximadamente um terço da capa e utiliza uma fonte na cor vermelha. Já na chamada “71 Ideias para 2005" (2005, n79) o número 71, escrito na cor laranja, ocupa integralmente a capa da revista.

\begin{tabular}{ll}
\hline Chamadas de Capa & Edição, Mês e Ano \\
\hline $\begin{array}{l}\text { Você tem apenas duas páginas e } 40 \text { segundos para se vender. Mas } \\
\text { nós temos } 25 \text { regras infalíveis para o seu currículo brilhar. }\end{array}$ & n.29, novembro de 2000 \\
Quebre os 12 hábitos que ameaçam sua carreira. & n.37, julho de 2001 \\
61 atitudes para turbinar sua carreira. & n.48, junho de 2002 \\
71 ideias para 2005. & $n .79$, janeiro de 2005 \\
33 lições de sucesso. & $n .106$, abril de 2007 \\
56 atitudes infalíveis para fortalecer sua carreira. & $n .128$, fevereiro de 2009 \\
8 sinais de que você merece reconhecimento. & $n .144$, junho de 2010 \\
\hline
\end{tabular}

Figura 1 - Chamadas de capa que podem ser relacionadas com características de quantofrenia.

Nota. Fonte: dados da pesquisa.

A intensificação do uso de números que podem atribuir ou despertar uma compreensão de certa neutralidade ou cientificidade às chamadas de capa é algo que se mostra acentuado nessa revista popular de negócios. Entretanto, não é possível atribuir-lhe exclusividade a essa característica de prescrição de modos de ser e de agir que ditam o estilo de vida condizente com a sociedade líquido-moderna (Bauman, 2009). Revistas que têm como categorias: saúde, lazer, viagem, entre outras, também oferecem prescrições com uso de números que, em geral, não são múltiplos de dez. Porém, especificamente nessa revista popular de negócios, os números indicaram maneiras, dicas, tipos, passos, lições, atitudes, exigências, ideias, ações e contemplaram muitos verbos e adjetivos que apresentam soluções para o cotidiano profissional em diversas áreas de atuação, conforme também constatado por Wood e Paula (2002). Na arena das escolhas plurais, para lembrar Giddens (2002), eles podem ser considerados elementos básicos das orientações de estilo de vida.

A insignificância e a quantofrenia podem ser consideradas duas figuras do poder gerencialista (Gaulejac, 2007). Se a primeira permite evitar a crítica e a contestação, pois é impeditiva de alcançar o sentido dos mecanismos que estão em prática, a segunda permite apresentar como neutro e objetivo um programa que leva os agentes a interiorizar a ideologia gerencialista. Tomando-se em questão o uso de números na apresentação das noções de carreira e de sucesso na última década da revista popular de negócios, é pertinente resgatar o entendimento referente à quantofrenia no sentido de que o recorte, a cifração, os cálculos e as estatísticas encontram-se associados à crença de uma representação objetiva dos fenômenos, conforme alertara Gaulejac (2007).

O modo explícito ou latente de apresentação das categorias de análise pode ser visualizado na Tabela 3.

Tabela 3:

Forma de apresentação das categorias de análise nas chamadas de capa - por categoria. Revista Você S/A - 156 edições

\begin{tabular}{lcccccc}
\hline \multirow{2}{*}{ Temas } & \multicolumn{2}{c}{ Total } & \multicolumn{2}{c}{ Explícito } & \multicolumn{2}{c}{ Latente } \\
\cline { 2 - 7 } & Qtd. & $\%$ & Qtd. & $\%$ & Qtd. & $\%$ \\
\hline Carreira & 164 & $77,00 \%$ & 61 & $37,20 \%$ & 103 & $62,80 \%$ \\
Sucesso & 30 & $14,10 \%$ & 17 & $56,70 \%$ & 13 & $43,30 \%$ \\
Carreira e Sucesso & 19 & $8,90 \%$ & 1 & $5,30 \%$ & 18 & $94,70 \%$ \\
(simultaneamente) & 213 & $100,00 \%$ & 79 & $37,10 \%$ & 134 & $62,90 \%$ \\
\hline \multicolumn{1}{c}{ Total Geral } & & &
\end{tabular}

Nota. Fonte: dados da pesquisa. 
A Tabela 3 apresenta o modo (explícito ou latente) como as chamadas foram relacionadas com as categorias de análise, com ênfase no modo latente $(62,90 \%$ do total das 213 chamadas de capa relacionadas às categorias de análise). Observa-se que do total de chamadas relativas às categorias de análise, 77\% concentraram-se na categoria carreira.

A análise do conteúdo das matérias relativas às chamadas de capa e referentes à carreira e sucesso possibilitou identificar o modo prescritivo com que ideias, soluções, dicas, atitudes, hábitos são apresentados aos leitores. A prescrição de caminhos a serem percorridos para a obtenção de sucesso na carreira, em geral, se faz acompanhar de uma forma verbal afirmativa e imperativa: “Quebre os 12 hábitos que ameaçam sua carreira" (2001, n³7); e "Seja o líder que as empresas precisam" (2005, $n^{\circ} 82$ ). Cabe ressaltar que tais prescrições não ressaltam a importância dos diversos contextos nos quais os leitores podem estar inseridos, como sua formação, experiências ou outros fatores passíveis de interferências na obtenção de resultados de sucesso.

As prescrições relativas à carreira e ao sucesso suportam-se na ideia de que cabe aos sujeitos adequarem-se ao mundo das organizações, como se nota em "Carreira: enfrente as mudanças do mercado e garanta seu crescimento" (2008, $\left.n^{\circ} 126\right)$ ou "Virou gerente! Veja como se adequar ao novo cargo" (2008, n¹25). Um alerta sobre isso já havia sido pronunciado por Gaulejac (2007, p. 78): “O indivíduo submetido à gestão deve adaptar-se ao 'tempo do trabalho', às necessidades produtivas e financeiras. As adaptabilidades e a flexibilidade são exigidas em mão única: cabe ao homem adaptar-se ao tempo da empresa e não o inverso".

A naturalização da prescrição de adequações às exigências sempre renovadas condiz com a lógica da sociedade líquido-moderna, em que "a síndrome consumista degradou a duração e promoveu a transitoriedade" (Bauman, 2009, p. 109), em que as pessoas passam a ser tratadas como produtos substituíveis de acordo com um dado prazo de validade. Nesse sentido, são ilustrativas as chamadas "Você é um pro-du-to: e tem que se conhecer muito bem para não ficar encalhado na prateleira" (2000, $n^{\circ} 21$ ) e "Qual sua data de validade?" (2001, n³5), que anunciam um estilo de vida assim caracterizado: "Os consumidores experientes não se incomodam em destinar as coisas ao lixo; ils (et elles, bien sûr) ne regrettent rien - aceitam a curta duração das coisas e seu desaparecimento predeterminado com tranquilidade, ou por vezes com uma satisfação mal disfarçada" (Bauman, 2009, p. 110). Caberia aos indivíduos, desse modo, adequar-se às carreiras proteanas (Hall \& Moss, 1998) ou sem-fronteiras (Defillippi \& Arthur, 1994), considerando as prescrições que a revista Você S/A contribui para divulgar e legitimar.

\section{Considerações Finais}

À luz do conceito de quantofrenia gerencialista na sociedade líquido-moderna, o estudo realizado objetivou destacar e analisar as noções de carreira e de sucesso apresentadas por uma revista popular de negócios. A revista atua na divulgação e legitimação de uma perspectiva gerencialista, uma vez que as noções de carreira e sucesso apresentadas condizem com a gestão gerencialista, tal como é apresentada por Gaulejac (2007) e tendem a prescrever o estilo de vida condizente com as demandas do trabalho imaterial e da gestão característicos de uma sociedade líquido-moderna.

Cabe ressaltar que a lógica gerencialista não é exclusividade dessa revista, mas uma lógica da sociedade dita líquido-moderna, caracteristicamente voltada ao consumo - de objetos, de modos de ser, de estilo de vida, enfim - e que busca apresentar padrões de homogeneização a serem seguidos por todos. "Nas revistas sobre estilo de vida, responsáveis por ditar padrões, as colunas dedicadas a 'novidades' ou sobre 'o que é in' (o que você deve ter, fazer e ser visto com e fazendo) aparecem ao lado daquelas que definem 'o que é out' (o que você não deve ter ou fazer, nem ser visto com e fazendo)" (Bauman, 2009, p.111).

As análises realizadas evidenciaram a quantofrenia nas chamadas de capa da revista Você S/A, em relação às categorias carreira e sucesso que, em geral, prescrevem os modos de ser e agir para a obtenção de sucesso profissional, o que implica, portanto, no estilo de vida. O uso de números nas chamadas de capa da revista pode ser compreendido como uma forma de obter maior atenção do público-alvo da revista, ou mesmo uma tentativa de atender a necessidade de soluções rápidas buscadas pelos leitores. Esse destaque é evidenciado especialmente quando são utilizados números não múltiplos de dez, fato que presume a tentativa de atribuir certa exaustão na busca de possibilidades ou cientificidade ou, ainda, uma procura por uma aparente incontestabilidade ao que é divulgado.

Em relação a isso é pertinente ressaltar que: 
[...] a aplicação de uma modelagem matemática não fornece os meios para refletir sobre as origens e sobre as significações desses modelos. Os instrumentos que parecem ser os mais 'objetivos', como os quadros de organização, os balanços de atividades, os dados financeiros, induzem hábitos, esquemas mentais e comportamentos. Eles modelam a realidade conforme normas preestabelecidas, que se tornam indiscutíveis. Isso explica sua onipotência e a pequena quantidade de críticas de que é objeto por partes de agentes que sofrem seus efeitos (Gaulejac, 2007, p. 101).

Por outro lado, o uso de uma quantidade descritiva de ações a serem realizadas também pode sugerir que a simples concretização desse passo-a-passo seja suficiente, na grande maioria das vezes, para obter determinado objetivo, como se dependesse somente do próprio indivíduo, que necessita apenas realizar todos os passos, dicas, planos, atitudes e ideias para alcançar o sucesso em sua carreira. Dessa forma, pode-se buscar minimizar a importância das questões econômicas, culturais, sociais e outras relacionadas ao contexto do mundo do trabalho.

Da mesma forma, também sugerem aos leitores, implícita ou explicitamente, que atitudes individuais sejam suficientes para enfrentar as adversidades decorrentes do cenário. Para isso, utilizam-se de uma lógica de causa e efeito, que poderia ser considerada simplista ao desconsiderar a diversidade de questões que estão envolvidas e são deixadas de fora ou são apenas superficialmente abordadas. Essa lógica prescritiva apresentada pela revista sugere, aparentemente, que bastaria o indivíduo executar tais procedimentos para que o resultado esperado e premeditado venha a ser alcançado. Por outro lado, caso o resultado não se apresente de acordo com o esperado, a culpabilização poderia ser atribuída ao próprio indivíduo que não foi suficientemente competente ou focado para cumprir a prescrição conforme recomendado.

Ou seja, é possível configurar um arranjo severo, no qual os fatores passíveis de serem considerados na elaboração da situação que não permitiu o alcance de um objetivo almejado passam a ser obscurecidos pelo prévio deslocamento da responsabilidade para o nível de engajamento da pessoa com o cumprimento do roteiro prescrito.

Por consequência, nos casos em que o êxito não é alcançado, é provável que reflexos negativos sejam associados. Dessa forma, a aplicação da lógica gerencialista na vida profissional ou pessoal dos indivíduos pode levá-los a desenvolver reações de frustração, sentimento de impotência e redução significativa de autoestima. Ou, ainda, como apontado por Tanure, Carvalho e Andrade (2007), pode-se configurar como uma situação de (in)sucesso.

Como limitações deste trabalho, podem ser citadas a delimitação do estudo, em especial, às chamadas de capa e a realização do estudo com uma única revista de negócios que, apesar de possuir tiragem bem expressiva para denotar uma ampla circulação dentro de seu público-alvo, não permite generalizações para as demais revistas de negócios.

Para pesquisas futuras sugerem-se estudos que possam verificar as decorrências da aplicação da lógica gerencialista na vida pessoal e profissional de indivíduos que a adotaram, bem como a realização de estudos com uma maior abrangência de revistas de negócios que possam identificar outros mecanismos de estabelecimento e perpetuação da lógica gerencialista, além da quantofrenia e prescrição de estilo de vida. Desse aumento expressivo no uso dos números nas capas, poder-se-ia fazer, ainda, diversas análises, seja com as questões econômicas nacionais e internacionais, seja com as políticas públicas e governos do período, sugestão que segue como indicação para possíveis estudos a serem realizados.

Acredita-se que o problema e os objetivos mostram-se instigantes por tratarem de dimensões para as quais não se tem resposta 'definitiva' na compreensão do trabalho no contexto do século XXI, particularmente sob o olhar da gestão de pessoas.

\section{Notas}

1.Os autores agradecem ao CNPq e à CAPES pelo apoio financeiro, bem como aos dois avaliadores anônimos pelas críticas e recomendações.

\section{Referências}

Arthur, M. B., \& Rousseau, D. M. (1996). Introduction: the boundaryless career as a new employment principle. In M. B. Arthur, \& D. M. Rousseau (Orgs.), The boundaryless career. a new employment principle for a new organizational era (pp. 3-20). New York: Oxford University Press.

Bauman, Z. (2009). Vida líquida. Rio de Janeiro: Jorge Zahar Editores. 
Bridges, W. (1995). Mudanças nas relações de trabalho. São Paulo: Makron Books.

Defillippi, R. J., \& Arthur, M. B. (1994). The boundaryless career: a competency-based perspective. Journal of Organizational Behavior, 15(4), 307-324.

Eccel, C. S., Grisci, C. L. I., \& Tonon, L. (2010). Representações do corpo em uma revista de negócios. Psicologia \& Sociedade, 22(2), 309-317.

Editora Abril. (2014). [Apresenta informações gerais sobre a Revista Você S.A.]. Recuperado de http://www.publiabril.com.br/marcas/vocesa/revista/informacoes-gerais

Flach, L., Grisci, C. L. I., Silva, F. M., \& Manfredini, V. (2009). Sofrimento psíquico no trabalho contemporâneo: analisando uma revista de negócios. Psicologia \& Sociedade, 21(2), 193-202.

Fontenelle, I. A. (2005, setembro). "Eu Proteu": a auto-gestão de carreira entre fatos e mitos. Anais do Encontro da Associação Nacional de Pós-Graduação e Pesquisa em Administração, Brasília, DF, Brasil, 29.

Gaulejac, V. de. (2007). Gestão como doença social: ideologia, poder gerencialista e fragmentação social. São Paulo: Ideias e Letras.

Gorz, A. (2005). O imaterial: conhecimento, valor e capital. São Paulo: Annablume.

Giddens, A. (2002). Modernidade e Identidade. Rio de Janeiro: Zahar.

Hall, D. T., \& Mirvis, P. H. (1996). The new protean career: psychological success and the path with a heart. In D. T. Hall (Org.), The career is dead, long live the career, a relational approach to careers (pp. 15-45). San Francisco: Jossey-Bass.

Hall, D. T., \& Moss, J. (1998). The new protean career contract: helping organizations and employees adapt. Organizational Dynamics, 26(3), 22-37.

Heloani, J. R., \& Capitão, C. G. (2012) Sexualidade e trabalho na visão da psicanálise. In M. E. de Freitas, \& M. Dantas (Orgs.), Diversidade sexual e trabalho (pp. 23-49). São Paulo: Cengage Learning.

Ituassu, C. T., \& Tonelli, M. J. (2011, novembro). Notas sobre o conceito de sucesso: sentidos construídos e possíveis ressignificações. Anais do Encontro de Gestão de Pessoas da Associação Nacional de Pós-Graduação e Pesquisa em Administração, João Pessoa, PB, Brasil, 3.

Mansano, S. V. R. (2009). Sorria, você está sendo controlado: resistência e poder na sociedade de controle. São Paulo: Summus.

Minayo, M. C. de S. (Org.). (2003). Pesquisa social: teoria, método e criatividade. Rio de Janeiro: Vozes.

Paiva, V. (1998). Educação e mundo do trabalho: notas sobre formas alternativas de inserção de setores qualificados. Contemporaneidade e Educação, 3(4), 8-21.

Sant'anna, D. B. de. (2001). Corpos de passagem: ensaios sobre a subjetividade contemporânea. São Paulo: Estação Liberdade.

Sennett, R. (2009). A corrosão do caráter: consequências pessoais do trabalho no novo capitalismo. Rio de Janeiro: Record.

Silva, G. T. F. da. (2010). As crises financeiras mundias de 1929 e 2008: uma análise comparativa a partir da abordagem pós-keynesiana (Dissertação de mestrado). Universidade Federal do Rio Grande do Sul, Porto Alegre, RS.

Strinati, D. (1999). Cultura popular: uma introdução. São Paulo: Hedra.

Tanure, B., Carvalho, A., Neto, \& Andrade, J. (2007). Executivos: sucesso e (in)felicidade. Rio de Janeiro: Elsevier.

Velloso, J. P. R., \& Albuquerque, R. C. (2009). Na crise global, como ser o melhor dos BRICS. Rio de Janeiro: Elsevier.

Wood, T., Jr., \& Paula, A. P. P. (2002, setembro). Pop-management: pesquisa sobre as revistas populares de gestão no Brasil. Anais do Encontro da Associação Nacional de Pós-Graduação e Pesquisa em Administração. Salvador, BA, Brasil, 26.

Wood, T., Jr., \& Caldas, M. P. (2005). Produção científica em administração no Brasil: o estado da arte. São Paulo: Atlas. 